\title{
Blickdiagnose
}

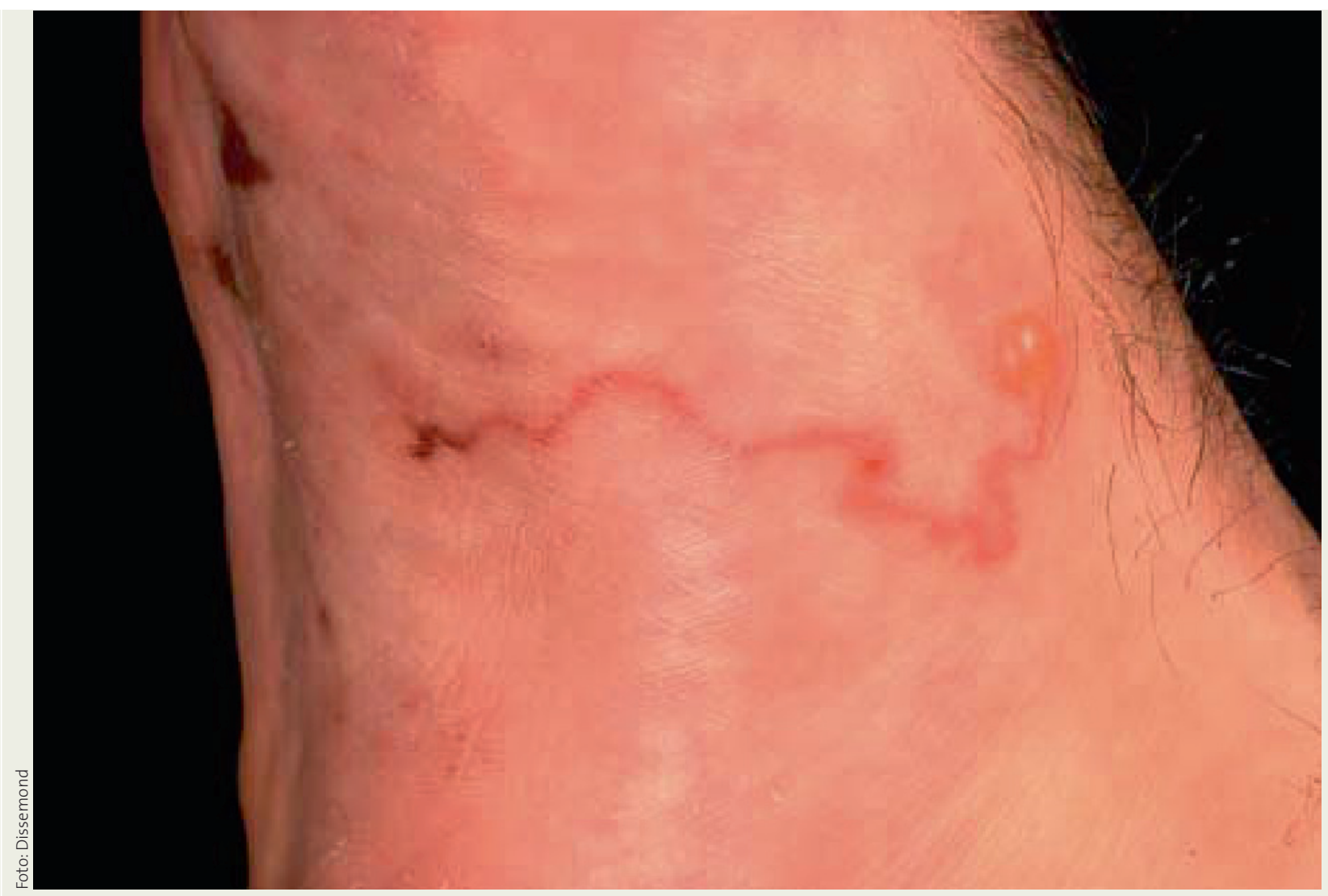

\section{Vom Urlaub gezeichnet}

Ein 37-jähriger Patient hatte zwei Wochen Urlaub in Kenia verbracht. Dort war er auch baden und hat sich im Sand liegend gesonnt. Unmittelbar nach Rückkehr seien ihm die Hautveränderungen erstmalig aufgefallen.

Der Patient beschrieb eine Größenzunahme der sehr stark juckenden bogenförmigen Hautveränderung um ca. $0,5 \mathrm{~cm}$ pro Tag.

Klinisch zeigte sich oberhalb des rechten Außenknöchels eine scharf begrenzte, gyrierte, lineäre Rötung mit diskreter oberflächlicher Entzündung und praller Blase am medialen Ende.

Es konnte eine Larva migrans, synonym auch als Hautmaulwurf oder Kriechkrankheit bezeichnet, diagnostiziert werden.

Die so genannte Larva migrans ist eine parasitäre Erkrankung, bei der Larven von Hakenwürmern, Pferdebremsen

\section{Ihr besonderer Fall?}

Sicher sehen auch Sie ab und an einen besonders eindrucksvollen Befund in Ihrer Praxis. Fotografieren Sie ihn, schreiben Sie uns unter dem Stichwort Blickdiagnose, bei Veröffentlichung erhalten Sie 100 Euro.

MMW-Fortschritte der Medizin

E-Mail: manhart@urban-vogel.de, Fax: 089/4372-1420 oder Fliegen in die menschliche Haut eindringen. Die Infektionsquellen sind meist Strände in tropischen und subtropischen Gebieten, die mit Hunde- oder Katzenkot verunreinigt sind. Die Larven bohren sich in die Kontaktflächen der Haut, beispielsweise beim Spaziergang ohne Schuhe oder Sonnenbad ohne Handtuch.

Als Therapie kann die Vereisung mit flüssigem Stickstoff oder die lokale Applikation von Thiabendazol (1 g in $10 \mathrm{~g}$ Vaseline $2 x$ täglich auftragen) für eine Woche versucht werden. Bei therapierefraktären Verläufen kann Thiabendazol (50 mg/kg KG) für drei Tage oder Ivermectin (12 mg) einmalig auch peroral verabreicht werden.

- PD Dr. med. Joachim Dissemond,

Oberarzt Universitätsklinikum Essen, Klinik und Poliklinik für Dermatologie, Venerologie und Allergologie, Hufelandstraße 55, D-45122 Essen

Keyword: Larva migrans

Weitere interessante Blickdiagnosen finden Sie in unserem Online-Archiv unter www.mmw.de. 